\title{
Phylogeny of the Ammonia-Producing Ruminal Bacteria Peptostreptococcus anaerobius, Clostridium sticklandii, and Clostridium aminophilum sp. nov.
}

\author{
BRUCE J. PASTER, ${ }^{1}$ JAMES B. RUSSELL, ${ }^{2,3 *}$ C. M. J. YANG, ${ }^{2}$ J. M. CHOW, ${ }^{3}$ \\ CARL R. WOESE, ${ }^{4}$ AND R. TANNER ${ }^{5}$ \\ Forsyth Dental Center, Boston, Massachusetts 02115'; Agricultural Research Service, U.S. Department of \\ Agriculture, ${ }^{2}$ and Section of Microbiology, Cornell University, ${ }^{3}$ Ithaca, New York 14853; Department of \\ Molecular Biology, University of Illinois, Champaign-Urbana, Illinois $61820^{4}$; and Department \\ of Botany and Microbiology, University of Oklahoma, Norman, Oklahoma $73019^{5}$
}

\begin{abstract}
In previous studies, gram-positive bacteria which grew rapidly with peptides or an amino acid as the sole energy source were isolated from bovine rumina. Three isolates, strains $C, F^{T}$ ( $T=$ type strain), and $S R$, were considered to be ecologically important since they produced up to 20-fold more ammonia than other ammonia-producing ruminal bacteria. On the basis of phenotypic criteria, the taxonomic position of these new isolates was uncertain. In this study, the $16 \mathrm{~S}$ rRNA sequences of these isolates and related bacteria were determined to establish the phylogenetic positions of the organisms. The sequences of strains $C, F^{T}$, and $S R$ and reference strains of Peptostreptococcus anaerobius, Clostridium sticklandii, Clostridium coccoides, Clostridium aminovalericum, Acetomaculum ruminis, Clostridium leptum, Clostridium lituseburense, Clostridium acidiurici, and Clostridium barkeri were determined by using a modified Sanger dideoxy chain termination method. Strain $\mathrm{C}$, a large coccus purported to belong to the genus Peptostreptococcus, was closely related to $P$. anaerobius, with a level of sequence similarity of $\mathbf{9 9 . 6 \%}$. Strain SR, a heat-resistant, short, rod-shaped organism, was closely related to $C$. sticklandii, with a level of sequence similarity of $99.9 \%$. However, strain $F^{T}$, a heat-resistant, pleomorphic, rod-shaped organism, was only distantly related to some clostridial species and $P$. anaerobius. On the basis of the sequence data, it was clear that strain $F^{T}$ warranted designation as a separate species. The closest known relative of strain $\mathrm{F}^{\mathrm{T}}$ was $C$. coccoides (level of similarity, only $90.6 \%$ ). Additional strains that are phenotypically similar to strain $F^{T}$ were isolated in this study. On the basis of phenotypic and phylogenetic differences, we believe that strain $F^{T}$ represents a new species of the genus Clostridium, for which we propose the name Clostridium aminophilum.
\end{abstract}

The rumen is one of the best-studied microbial habitats $(2$, $16-18,28)$, and for many years it was assumed that the predominant classes of ruminal microorganisms had been isolated (25). Much of the protein which enters the rumen is fermented, but Bladen et al. (1) noted that most pure cultures of ruminal bacteria were unable to produce ammonia. Strains of Bacteroides ruminicola, Megasphaera elsdenii, Selenomonas ruminantium, Eubacterium ruminantium, and Butyrivibrio fibrisolvens produced some ammonia, but less than $25 \%$ of the casein hydrolysate was converted to ammonia even though the incubation period was $96 \mathrm{~h}$. Nonetheless, "on the basis of numbers of strains and amount of ammonia produced," Bladen et al. (1) concluded that "Bacteroides ruminicola is usually the most important ammonia-producing bacterium in the rumen of mature cattle." All of these ammonia-producing bacteria fermented carbohydrate, and the isolation media contained carbohydrates and a low concentration of Trypticase (3).

Later work indicated that strain $\mathrm{B}_{1} 4$ of Bacteroides ruminicola, the most active strain examined by Bladen et al. (1), had a specific activity of ammonia production which was less than the specific activity of mixed cultures of ruminal microorganisms $(14,24)$. Interspecies hydrogen transfer and methanogenesis increased the capacity of mixed ruminal bacterial cultures to produce ammonia, but this effect could not explain the low level of activity of the pure cultures (14). Protozoa also produced some ammonia, but their activity

\footnotetext{
* Corresponding author.
}

was even lower than the activity of the bacteria, particularly when the amino acid source was soluble (15). The feed additive monensin decreases ammonia production in vitro and in vivo $(13,14)$, but the most active ammonia-producing ruminal bacteria were monensin resistant $(11,12)$.

On the basis of this previous work, it appeared that very active amino acid-fermenting bacteria had not yet been isolated from the rumen. Enrichment cultures which contained Trypticase as the sole nitrogen source and lactate, dulcitol, pectin, or xylose as an energy source yielded strains of $M$. elsdenii, S. ruminantium, Bacteroides ruminicola, and Butyrivibrio fibrisolvens, respectively (26), but none of these bacteria had specific activities of ammonia production which were greater than the specific activities of the bacteria examined by Bladen et al. (1). When the concentration of Trypticase was increased and other energy sources were omitted, a large gram-positive coccus was isolated (strain C [26]), and this isolate had a specific activity of ammonia production which was nearly 20 -fold greater than that of Bacteroides ruminicola $\mathrm{B}_{1} 4$ (24). Later isolations yielded two more gram-positive bacteria, a pleomorphic rod-shaped organism (strain $\mathrm{F}^{\mathrm{T}}[\mathrm{T}=$ type strain]) and a short rod-shaped organism (strain SR) $(7-10,29)$, which could not utilize carbohydrates as energy sources for growth. These recently isolated amino acid-fermenting bacteria have not been enumerated extensively, but they were found at significant numbers in the rumen $(8,26)$. Their susceptibility to the feed additive monensin is consistent with the "amino acid-sparing" effect of this antibiotic (13).

Strain C belonged to the genus Peptostreptococcus and 
was closely related to Peptostreptococcus anaerobius. Strain SR was identified as a strain of Clostridium sticklandii. However, strain $\mathrm{F}^{\mathbf{T}}$ could not be identified on the basis of conventional taxonomic characteristics and 16S rRNA sequence similarity, and consequently we propose the establishment of a new species for this organism, Clostridium aminophilum.

\section{MATERIALS AND METHODS}

Bacterial strains, growth conditions, and assays. The growth conditions and assays used for strain $\mathrm{C}, P$. anaerobius ATCC $27237^{\mathrm{T}}$, strain $\mathrm{F}^{\mathrm{T}}$, and strain $\mathrm{SR}$ have been described previously (8).

Additional isolates similar to strain $\mathbf{F}^{\mathbf{T}}$. Rumen contents were obtained from ruminally fistulated, nonlactating dairy cows on several different days. The cows were fed $2.5 \mathrm{~kg}$ of timothy hay or $2.5 \mathrm{~kg}$ of timothy hay plus $2.5 \mathrm{~kg}$ of commercial concentrate supplement ( $16 \%$ crude protein) twice daily. The ruminal contents were squeezed through cheesecloth and left undisturbed for $20 \mathrm{~min}$. Once the feed particles were buoyed up by gas production and the protozoa had settled to the bottom of the flask used, mixed ruminal bacteria from the central layer were then transferred to an anaerobic broth containing salts, vitamins, microminerals, cysteine (26), $0.5 \mathrm{~g}$ of yeast extract per liter, and $15 \mathrm{~g}$ of Casamino Acids (Difco, Detroit, Mich.) per liter.

Tenfold dilutions containing Casamino Acids contained an abundance of irregularly shaped cells, and the $10^{-7}$ dilutions were streaked onto plates containing $2 \%$ agar in an anaerobic glove box (Coy Laboratory Products, Ann Arbor, Mich.). The medium contained salts, vitamins, microminerals, cysteine (26), $0.5 \mathrm{~g}$ of yeast extract per liter, $3 \mathrm{~g}$ of Trypticase (BBL Microbiology Systems, Cockeysville, Md.) per liter, and $0.1 \mathrm{~g}$ of glutamate per liter. Large, circular, translucent colonies yielded pure cultures which resembled strain $\mathbf{F}^{\mathbf{T}}(8)$.

Fatty acids and polyacrylamide gel electrophoresis. Cellular fatty acid analyses and polyacrylamide gel electrophoresis were performed by methods that were described previously (20).

Isolation and purification of rRNAs. rRNAs were isolated and partially purified by using the procedure of Pace et al. (22), as described by Paster and Dewhirst (23).

16S rRNA sequencing. Nearly complete 16S rRNA sequences were determined by a Sanger dideoxy chain termination technique in which seven primers complementary to universally conserved regions are elongated with reverse transcriptase (19). The procedure was modified to reduce termination bands (23).

Sequence analyses. RNA sequence, sequence alignment, secondary structure, similarity matrix, and phylogenetic trees were analyzed by a Microsoft Quick BASIC program, using an IBM PC-AT computer as previously described (23). The data base contained RNA sequences from approximately 350 different bacterial species. These sequences were obtained from previously published articles, unpublished data that were provided by other scientists, and unpublished data from our own laboratory. Only those regions that could be unambiguously aligned were used to construct similarity matrices. The neighbor-joining method of Saitou and Nei (27) was used to construct phylogenetic trees.

Nucleotide sequence accession numbers. The sequences of the microorganisms which we investigated are available for electronic retrieval from GenBank under accession numbers L04166 (for strain C), L04168 (for $P$. anaerobius ATCC $27237^{\mathrm{T}}$ ), L04165 (for $C$. aminophilum $\mathrm{F}^{\mathrm{T}}\left[=\operatorname{VPI} 14602^{\mathrm{T}}\right]$ ), and L04167 (for strain SR [= VPI 14603]). The accession numbers for reference strains that have been deposited previously by Woese (31) are as follows: M59107 for Clostridium lituseburense ATCC 25759, M59084 for Clostridium acidiurici ATCC 7906, M23927 for Clostridium barkeri ATCC 25849, M26494 for Clostridium stocklandii, M59090 for Clostridium coccoides ATCC 29236, M59083 for Acetomaculum ruminis ATCC 43876, M23929 for Clostridium aminovalericum VPI 4212, and M59095 for Clostridium leptum ATCC 29065.

\section{RESULTS AND DISCUSSION}

In this study, the phylogenetic positions of previously unidentified strains $C, S R$, and $F^{T}$ were determined because of their potential ecological importance in the bovine rumen. Unlike other ruminal bacteria, these organisms were unusual in that they were able to produce relatively high levels of ammonia from amino acids or peptides. We determined approximately $95 \%$ of the total sequences for strains C, SR, and $F^{\mathbf{T}}$ and the type strain of $P$. anaerobius. A similarity matrix derived from 1,256 base comparisons of 16S rRNA sequences of these strains, reference gram-positive species, and Escherichia coli are shown in Table 1. A dendrogram constructed from the similarity data is shown in Fig. 1.

On the basis of the sequence data, strain SR and the reference strain of $C$. sticklandii were determined to be essentially identical, with $99.9 \%$ sequence similarity. The differences in bases may be attributed to strain variation or sequence error. According to Bergey's Manual of Systematic Bacteriology (5), the biochemical traits of $C$. sticklandii are in agreement with those observed for strain SR (8). Furthermore, strain SR was verified as $C$. sticklandii on the basis of its phenotypic reactions, its cellular fatty acid content, and the electrophoretic patterns of its cellular proteins (19b). This is the first report of $C$. sticklandii being isolated from the bovine rumen.

The polyacrylamide gel electrophoresis protein pattern, the cellular fatty acids, and certain physiological characteristics of strain C differed from the characteristics of the type strain of $P$. anaerobius (strain ATCC 27237) (19a), but strain C exhibited $99.6 \%$ sequence similarity to $P$. anaerobius. On the basis of the latter result, it is suggested that strain $C$ should be classified as a strain of $P$. anaerobius, although DNA-DNA hybridization studies will be necessary to confirm this classification.

The organisms which we examined fell into two phylogenetic clusters (Fig. 1). The first group contained strain $\mathrm{F}^{\mathrm{T}}, C$. coccoides, $C$. aminovalericum, $A$. ruminis, and, more distantly, $C$. leptum. The average level of similarity between members of this group was $86.4 \%$. The second group contained strain $\mathrm{C}, P$. anaerobius, $C$. lituseburense, $C$. sticklandii (and strain SR), $C$. acidiurici, and $C$. barkeri. The average level of similarity between members of this group was $85.2 \%$. The average level of similarity between members of the two groups was $81.7 \%$.

On the basis of previously described phenotypic data, the taxonomic placement of strain $\mathrm{F}^{\mathrm{T}}$ could not be determined $(6,8,21)$. However, from the sequence data (Table 1 and Fig. 1), it is clear that strain $\mathrm{F}^{\mathbf{T}}$ warrants designation as a separate species in the genus Clostridium as it is presently defined. The closest relative of strain $\mathbf{F}^{\mathbf{T}}$ is $C$. coccoides (90.6\% similarity) (Table 1 ). Strain $\mathrm{F}^{\mathrm{T}}$ is a gram-positive, anaerobic, rod-shaped organism that forms spores (albeit infrequently). Although the $\mathrm{G}+\mathrm{C}$ content of the DNA is 52.5 mol\%, which is considered high for most clostridia, there are 
TABLE 1. Similarity matrix derived from 1,256 base comparisons of $16 \mathrm{~S}$ rRNA sequences for various species of clostridia and related bacteria

\begin{tabular}{|c|c|c|c|c|c|c|c|c|c|c|c|c|}
\hline \multirow[b]{2}{*}{ Species or strain } & \multicolumn{12}{|c|}{$\%$ Similarity ${ }^{a}$ to: } \\
\hline & $\begin{array}{c}\text { C. amino- } \\
\text { philum } \\
\mathrm{F}^{\mathrm{T}}\end{array}$ & $\begin{array}{l}\text { C. coc- } \\
\text { coides }\end{array}$ & $\begin{array}{l}\text { C. amino- } \\
\text { valericum }\end{array}$ & $\begin{array}{l}\text { A. num- } \\
\text { inis }\end{array}$ & $\begin{array}{l}\text { C. lep- } \\
\text { tum }\end{array}$ & $\begin{array}{l}\text { P. anaero- } \\
\text { bius } \mathrm{C}\end{array}$ & $\begin{array}{c}P . \text { anaero- } \\
\text { bius ATCC } \\
27337^{\mathrm{T}}\end{array}$ & $\begin{array}{l}\text { C. lituse- } \\
\text { burense }\end{array}$ & $\begin{array}{c}\text { C. stick- } \\
\text { landii } \\
\text { (strain SR) }\end{array}$ & $\begin{array}{c}\text { C. acid- } \\
\text { iurici }\end{array}$ & $\begin{array}{l}\text { C. bark- } \\
\text { eri }\end{array}$ & E. coli \\
\hline C. aminophilum $\mathrm{F}^{\mathrm{T}}$ & & 90.6 & 88.3 & 87.0 & 82.8 & 81.5 & 81.3 & 81.7 & 81.2 & 82.4 & 79.9 & 77.1 \\
\hline C. coccoides & 90.0 & & 89.6 & 88.5 & 82.7 & 82.1 & 82.0 & 82.4 & 81.4 & 83.4 & 81.3 & 77.7 \\
\hline C. aminovalericum & 87.2 & 88.9 & & 88.1 & 81.9 & 83.0 & 82.8 & 83.5 & 82.9 & 84.1 & 81.0 & 78.6 \\
\hline A. ruminis & 85.7 & 87.6 & 87.1 & & 84.1 & 81.4 & 81.2 & 81.0 & 80.5 & 82.2 & 81.7 & 77.9 \\
\hline C. leptum & 80.5 & 80.3 & 79.2 & 82.2 & & 81.3 & 81.2 & 79.8 & 80.6 & 81.6 & 81.8 & 76.9 \\
\hline P. anaerobius $\mathrm{C}$ & 78.8 & 79.5 & 80.7 & 78.6 & 78.5 & & 99.6 & 90.2 & 88.4 & 84.4 & 81.9 & 76.4 \\
\hline P. anaerobius ATCC $27337^{\mathrm{T}}$ & 78.4 & 79.4 & 80.4 & 78.3 & 78.4 & 99.6 & & 90.1 & 88.4 & 84.3 & 82.0 & 76.7 \\
\hline C. lituseburense & 79.0 & 79.9 & 81.3 & 78.1 & 76.5 & 89.5 & 89.4 & & 87.5 & 85.3 & 82.2 & 76.9 \\
\hline C. sticklandii (strain SR) & 78.3 & 78.7 & 80.6 & 77.4 & 77.5 & 87.4 & 87.4 & 86.4 & & 84.3 & 81.2 & 77.1 \\
\hline C. acidiurici & 79.9 & 81.3 & 82.1 & 79.7 & 78.9 & 82.5 & 82.4 & 83.7 & 82.3 & & 86.9 & 76.6 \\
\hline C. barkeri & 76.5 & 78.5 & 78.1 & 79.0 & 79.1 & 79.3 & 79.4 & 79.7 & 78.4 & 85.7 & & 77.4 \\
\hline E. coli & 72.7 & 73.5 & 74.7 & 73.8 & 72.4 & 71.6 & 72.0 & 72.4 & 72.6 & 76.0 & 73.1 & \\
\hline
\end{tabular}

${ }^{a}$ Numbers above the diagonal are uncorrected percentages of similarity. Numbers below the diagonal represent percentages of similarity corrected for multiple base changes by the method of Jukes and Cantor (18a).

some species of clostridia that have $\mathrm{G}+\mathrm{C}$ contents as high as $55 \mathrm{~mol} \%$ (6). Because strain $\mathrm{F}^{\mathrm{T}}$ grew more rapidly with free amino acids than with peptides, we propose the name Clostridium aminophilum.

In this and other studies, analyses of 16S rRNA sequences of clostridia and related bacteria have shown that many of these bacteria are only distantly related $(4,30,32)$. The genus Clostridium contains a highly diverse group of bacteria, and we agree with Cato and Stackebrandt (6) that the old description of these organisms as strictly anaerobic, sporeforming rods is clearly inadequate. The clostridia are markedly diverse with regard to morphology, $\mathrm{G}+\mathrm{C}$ content of the DNA (ranging from 24 to $55 \mathrm{~mol} \%$ ), and metabolic activity (6). Some clostridia do not readily form spores (5). Since we believe that taxonomy should accurately reflect phylogenetic relationships, the taxonomy of the genus Clostridium should be reexamined.

Strains similar to $C$. aminophilum $\mathrm{F}^{\mathrm{T}}$ were easily recognized by the rather unusual cell morphology, and additional strains similar to the original isolate (8) were obtained from rumina. There was some variation in the growth rates of these organisms, but the patterns of amino acid fermentation were remarkably similar (Table 2 ). The most notable variation in the strain $\mathbf{F}^{\mathbf{T}}$-like isolates was variation in pyroglutamate fermentation. Strain $\mathbf{F}^{\mathbf{T}}$ converted pyroglutamate to acetate and butyrate, but more recent isolates had little capacity to degrade this amino acid.

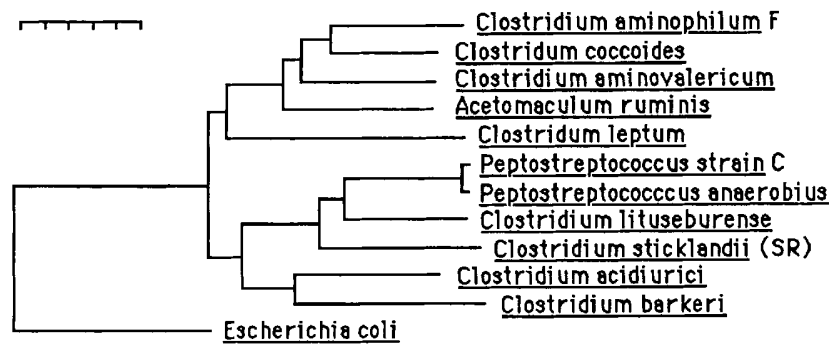

FIG. 1. Phylogenetic tree for the organisms examined in this study. The scale represents a 5\% difference in nucleotide sequences, as determined by adding all of the branch lengths connecting two species.
Description of Clostridium aminophilum sp. nov. Clostridium aminophilum (a.mi.no' phi.lum. chem. term amino, amino; G. adj. philos, loving; N.L. neut. adj. aminopilum, loving amino acids). Irregular gram-positive rods that are 1.0 $\mu \mathrm{m}$ wide and $1.5 \mu \mathrm{m}$ long. Cells are nonmotile and occasionally form central to subterminal endospores. Cells survive heating at $80^{\circ} \mathrm{C}$ for $10 \mathrm{~min}$. Obligately anaerobic. Grows at 25 and 37 to $39^{\circ} \mathrm{C}$, but not at $45^{\circ} \mathrm{C}$. Asaccharolytic. Grows on amino acids or peptides. Prefers glutamine, glutamate, serine, and histidine as carbon sources. Some strains are able to deaminate pyroglutamate. The major fermentation end products from Casamino Acids are ammonia, acetate, and butyrate (traces of lactate and succinate are also found).

TABLE 2. Ammonia production by $C$. aminophilum $\mathrm{F}^{\mathrm{T}}$, $\mathrm{F} 1, \mathrm{~F} 3, \mathrm{~F} 7$, and $\mathrm{F} 9^{a}$

\begin{tabular}{lrrrrr}
\hline & \multicolumn{5}{c}{ Ammonia production (nmol/mg of protein/min) } \\
\cline { 2 - 6 } \multicolumn{1}{c}{ Amino acid } & Strain & Strain & Strain & Strain & Strain \\
& F $^{\mathrm{T}}$ & F1 & F3 & F7 & F9 \\
\hline Glutamate & 402 & 424 & 476 & 269 & 310 \\
Pyroglutamate & 161 & 42 & 23 & 6 & 6 \\
Glutamine & 364 & 213 & 198 & 202 & 128 \\
Aspartate & 0 & 0 & 0 & 0 & 0 \\
Aspargine & 12 & 6 & 6 & 5 & 11 \\
Serine & 414 & 280 & 310 & 307 & 405 \\
Threonine & 174 & 128 & 114 & 86 & 162 \\
Histidine & 246 & 126 & 82 & 89 & 68 \\
Alanine & 44 & 29 & 59 & 55 & 42 \\
Glycine & 145 & 82 & 110 & 78 & 100 \\
Arginine & 0 & 0 & 0 & 0 & 0 \\
Lysine & 0 & 0 & 0 & 0 & 0 \\
Proline & 0 & 0 & 0 & 0 & 0 \\
Valine & 0 & 0 & 0 & 0 & 0 \\
Leucine & 0 & 0 & 0 & 0 & 0 \\
Isoleucine & 0 & 0 & 0 & 0 & 0 \\
Phenylalanine & 0 & 0 & 0 & 0 & 0 \\
Tyrosine & 7 & 4 & 4 & 3 & 3 \\
Tryptophan & 0 & 0 & 0 & 0 & 0 \\
Methionine & 0 & 0 & 0 & 0 & 0 \\
Cysteine & 174 & 83 & 80 & 57 & 37 \\
\hline
\end{tabular}

${ }^{a}$ The growth rates of the strains were as follows: strain $\mathrm{F}^{\mathrm{T}}, 0.37 \mathrm{~h}^{-1}$; strain $\mathrm{F} 1,0.14 \mathrm{~h}^{-1}$; strain $\mathrm{F} 3,0.11 \mathrm{~h}^{-1}$; strain $\mathrm{F} 7,0.13 \mathrm{~h}^{-1}$; and strain $\mathrm{F} 9,0.23 \mathrm{~h}^{-1}$. 
Hydrogen is not produced. Sodium is essential for growth. Tolerates $\mathrm{pH}$ 5.3. Indole and $\mathrm{H}_{2} \mathrm{~S}$ are produced. Gelatin is not hydrolyzed. Casein is not digested. Urease, lipase, lecithinase, and esculinase activities are not detected. Isolated from fistulated cattle. Strain F (= ATCC 49906) is the type strain; its $\mathrm{G}+\mathrm{C}$ content is $52.5 \mathrm{~mol} \%$ (as determined by the thermal denaturation method).

\section{ACKNOWLEDGMENTS}

We thank L. V. H. Moore for performing the cellular fatty acid analyses and polyacrylamide gel electrophoresis, Gayle Fraser for preparing some sequencing gels, and Thomas MacAdoo for suggestions concerning Latin nomenclature.

This research was supported by the U. S. Dairy Forage Research Center, Madison, Wis., by grant BSR 87-05352 from the National Science Foundation, and by Public Health Service grants DE-04881 and DE-08303) from the National Institutes of Health.

\section{REFERENCES}

1. Bladen, H. A., M. P. Bryant, and R. N. Doetsch. 1961. A study of bacterial species from the rumen which produce ammonia from protein hydrolysate. Appl. Microbiol. 9:175-180.

2. Bryant, M. P. 1959. Bacterial species of the rumen. Bacteriol. Rev. 23:125-153.

3. Bryant, M. P., and I. M. Robinson. 1961. An improved nonselective culture medium for ruminal bacteria and its use in determining diurnal variation in numbers of bacteria in the rumen. J. Dairy Sci. 4:1446-1455.

4. Canard, B., T. Garnier, B. Lafay, R. Cristen, and S. T. Cole. 1992. Phylogenetic analysis of the pathogenic anaerobe Clostridium perfringens using the $16 \mathrm{~S}$ rRNA nucleotide sequence. Int. J. Syst. Bacteriol. 42:312-314.

5. Cato, E. P., W. L. Georges, and S. M. Finegold. 1986. Genus Clostridium Prazmowski 1880, 23 ${ }^{\mathrm{AL}}$, p. 1141-1200. In P. H. A. Sneath, N. S. Mair, M. E. Sharpe, and J. G. Holt (ed.), Bergey's manual of systematic bacteriology, vol. 2. The Williams \& Wilkins Co., Baltimore.

6. Cato, E. P., and E. Stackebrandt. 1989. Taxonomy and phylogeny, p. 1-26. In N. P. Minton and D. J. Clarke (ed.), Clostridia. Plenum Press, New York.

7. Chen, G., and J. B. Russell. 1988. Fermentation of peptides and amino acids by a monensin-sensitive ruminal peptostreptococcus. Appl. Environ. Microbiol. 54:2742-2749.

8. Chen, G., and J. B. Russell. 1989. More monensin-sensitive, ammonia-producing bacteria from the rumen. Appl. Environ. Microbiol. 55:1052-1057.

9. Chen, G., and J. B. Russell. 1989. Sodium-dependent transport of branched-chain amino acids by a monensin-sensitive ruminal peptostreptococcus. Appl. Environ. Microbiol. 55:2658-2663.

10. Chen, G., and J. B. Russell. 1990. Transport and deamination of amino acids by a gram-positive, monensin-sensitive ruminal bacterium. Appl. Environ. Microbiol. 56:2186-2192.

11. Chen, M., and M. J. Wolin. 1979. Effect of monensin and lasalocid-sodium on the growth of methanogenic and rumen saccharolytic bacteria. Appl. Environ. Microbiol. 38:72-78.

12. Dennis, S. M., T. G. Nagaraja, and E. E. Bartley. 1981. Effects of lasalocid or monensin on lactate-producing and -using bacteria. Appl. Environ. Microbiol. 52:418-426.

13. Dinius, D. A., M. E. Simpson, and P. B. Marsh. 1976. Effect of monensin fed with forage on digestion and the ruminal ecosystem of steers. J. Anim. Sci. 42:229-234.

14. Hino, T., and J. B. Russell. 1985. The effect of reducing agent dispoand NADH/NAD on the deamination of amino acids by intact and cell-free extracts of rumen microorganisms. Appl. Environ. Microbiol. 50:1368-1374.
15. Hino, T., and J. B. Russell. 1986. Relative contributions of ruminal bacteria and protozoa to the degradation of protein in vitro. J. Anim. Sci. 64:261-270.

16. Hungate, R. E. 1966. The rumen and its microbes. Academic Press, New York.

17. Hungate, R. E. 1975. The rumen microbial ecosystem. Annu. Rev. Ecol. Syst. 6:39-66.

18. Hungate, R. E., M. P. Bryant, and R. A. Mah. 1964. The rumen bacteria and protozoa. Annu. Rev. Microbiol. 18:131-166.

18a.Jukes, T. H., and C. R. Cantor. 1969. Evolution of protein molecules, p. 21-132. In H. N. Munro (ed.), Mammalian protein metabolism, vol. 3. Academic Press, Inc., New York.

19. Lane, G. H., B. Pace, G. J. Olsen, D. A. Stahl, M. L. Sogin, and N. R. Pace. 1985. Rapid determination of 16 S ribosomal RNA sequences for phylogenetic analyses. Proc. Natl. Acad. Sci. USA 82:6955-6959.

19a.Moore, L. V. Personal communication.

19b.Moore, W. E. C. Personal communication.

20. Moore, W. E. C., D. E. Hash, L. V. Holdeman, and E. P. Cato. 1980. Polyacrylamide slab gel electrophoresis of soluble proteins for studies of bacterial floras. Appl. Environ. Microbiol. 39:900-907.

21. Moore, W. E. C., and L. V. Moore. 1986. Genus Eubacterium Prevot 1938, 294 ${ }^{\mathrm{AL}}$, p. 1353-1373. In P. H. A. Sneath, N. S. Mair, M. E. Sharpe, and J. G. Holt (ed.), Bergey's manual of systematic bacteriology, vol. 2. The Williams \& Wilkins Co., Baltimore.

22. Pace, B., E. A. Matthews, K. D. Johnson, C. R. Cantor, and N. R. Pace. 1982. Conserved 5S rRNA complement to tRNA is not required for protein synthesis. Proc. Natl. Acad. Sci. USA 79:36-40.

23. Paster, B. J., and F. E. Dewhirst. 1988. Phylogeny of campylobacters, wolinellas, Bacteroides gracilis, and Bacteroides ureolyticus by $16 \mathrm{~S}$ ribosomal ribonucleic acid sequencing. Int. J. Syst. Bacteriol. 38:56-62.

24. Russell, J. B. 1983. Fermentation of peptides by Bacteroides ruminicola $\mathrm{B}_{1} 4$. Appl. Environ. Microbiol. 45:1566-1574.

25. Russell, J. B. 1984. Factors influencing competition and composition of the rumen bacterial flora, p. 313-345. In F. M. C. Gilchrist and R. I. Mackie (ed.), Herbivore nutrition in the subtropics and tropics, Science Press, Craighall, South Africa.

26. Russell, J. B., H. J. Strobel, and G. Chen. 1988. Enrichment and isolation of a ruminal bacterium with a very high specific activity of ammonia production. Appl. Environ. Microbiol. 54:872-877.

27. Saitou, N., and M. Nei. 1987. The neighbor-joining method: a new method for reconstructing phylogenetic trees. Mol. Biol. Evol. 4:406-425.

28. Stewart, C. S., and M. P. Bryant. 1988. The rumen bacteria, p. 21-75. In P. N. Hobson (ed.), The rumen microbial ecosystem. Elsevier Applied Science, London.

29. Van Kessel, J. A. S., and J. B. Russell. 1992. Energetics of arginine and lysine transport by whole cells and membrane vesicles of strain SR, a monensin-sensitive ruminal bacterium. Appl. Environ. Microbiol. 58:969-975.

30. Weizenegger, M., M. Neumann, E. Stackebrandt, N. Weiss, and W. Ludwig. 1992. Eubacterium alctolyticum phylogenetically groups with Eubacterium limosum, Acetobacterium woodii and Clostridium barkeri. Syst. Appl. Microbiol. 15:32-36.

31. Woese, C. R. 1987. Bacterial evolution. Microbiol. Rev. 51:221271.

32. Zhao, H., D. Yang, C. R. Woese, and M. P. Bryant. 1990. Assignment of Clostridium bryantii to Syntrophospora bryantii gen. nov., comb. nov. on the basis of a $16 \mathrm{~S}$ rRNA sequence analysis of its crotonate-grown pure culture. Int. J. Syst. Bacteriol. 40:40-44. 